\title{
Surgical site infection after transoral versus posterior approach for atlantoaxial fusion: a matched-cohort study
}

\author{
Mohamed Macki, MD, MPH,, Azam Basheer, MD,, Ian Lee, MD, ${ }^{1}$ Ryan Kather, ${ }^{2}$ \\ Ilan Rubinfeld, MD, MBA, ${ }^{2}$ and Muwaffak M. Abdulhak, MD' \\ Departments of ${ }^{1}$ Neurosurgery and ${ }^{2}$ General Surgery, Henry Ford Hospital, Detroit, Michigan
}

\begin{abstract}
OBJECTIVE In the past, spine surgeons have avoided the transoral approach to the atlantoaxial segment because of concerns for unacceptable patient morbidity. The objective of this study was to measure 30-day postoperative complications, especially surgical site infection (SSI), after transoral versus posterior approach to atlantoaxial fusion.

METHODS The source population was provided by the American College of Surgeons National Surgical Quality Improvement Program database, which was queried for all patients who underwent atlantoaxial fusion for degenerative/ spondylotic disease and/or trauma between 2005 and 2014. To eliminate bias from unequal sample sizes, patients who underwent the transoral approach were matched with patients who underwent the posterior approach (generally 1:5 ratio) based on age \pm 5 years and modified frailty index score (a measure of preoperative comorbidity burden). Because of rare $\mathrm{SSI}$ incidence, adjusted odds ratios $\left(\mathrm{OR}_{\mathrm{adj}}\right)$ of $\mathrm{SSI}$ were calculated using penalized maximum likelihood estimation.

RESULTS A total of 318 patients were included in the study. There were no statistically significant differences between the transoral cohort $(n=56)$ and the posterior cohort $(n=262)$ in terms of 30 -day postoperative individual complications, including SSI (1.79\% vs 1.91\%; $p=0.951)$ and composite complications $(10.71 \%$ vs $6.87 \% ; p=0.323)$. Controlling for sex and smoking, the odds of SSI in the transoral approach were almost equal to the odds in the posterior approach $\left(\mathrm{OR}_{\mathrm{adj}}\right.$ $1.17 ; p=0.866)$. While the unplanned reoperation rate of $5.36 \%$ after transoral surgery was higher than the $1.53 \%$ rate after posterior surgery, the difference approached, but did not reach, statistical significance $(p=0.076)$.

CONCLUSIONS Transoral versus posterior surgery for atlantoaxial fusion did not differ in 30-day unexpected outcomes. Therefore, spinal pathology, rather than concern for postoperative complications, should adjudicate the technical approach to the atlantoaxial segment.

https://thejns.org/doi/abs/10.3171/2017.5.SPINE161064
\end{abstract}

KEY WORDS atlantoaxial; C-1; C-2; cervical; transoral; surgical site infection

I N 1917, Kanavel first described the transoral removal of a bullet fragment from the anterior arch of C-1. ${ }^{15}$ The application of this novel technique in other spinal diseases was conjured by Scoville and Sherman in 1951: "Future surgical advance [to an abnormally high odontoid process] lies in the development of a successful removal of the odontoid, possibly through the mouth." ${ }^{21}$ Since then, the transoral approach has been refined to provide an open surgical corridor to the caudal end of the clivus, the anterior arch of the atlas, and the odontoid process. ${ }^{9}$ The transor- al approach allows for anterior arthrodesis for atlantoaxial pathology, including arthritides (rheumatoid, psoriatic, and degenerative diseases) and trauma (e.g., odontoid fractures). ${ }^{7}$ In 1981, Dr. Harms first introduced anterior fusion of the atlantoaxial spine with a butterfly-shaped plate, which was subsequently revised in subsequent decades (Fig. 1). ${ }^{14,16,28}$ The operation entails odontoidectomy (decompression) followed by anterior plate arthrodesis.

Despite this unique addition to the surgeon's armamentarium to access the $\mathrm{C} 1-2$ segment, the operation is limited

ABBREVIATIONS ACS = American College of Surgeons; AIC = Akaike information criterion; CPT = Current Procedural Terminology; $\mathrm{mFI}=$ modified frailty index; NSQIP = National Surgical Quality Improvement Program; $\mathrm{OR}_{\mathrm{adj}}=$ adjusted odds ratio; $\mathrm{OR}_{\mathrm{unadj}}=$ unadjusted odds ratio; $\mathrm{SSI}=$ surgical site infection.

SUBMITTED September 7, 2016. ACCEPTED May 12, 2017.

INCLUDE WHEN CITING Published online October 27, 2017; DOI: 10.3171/2017.5.SPINE161064. 


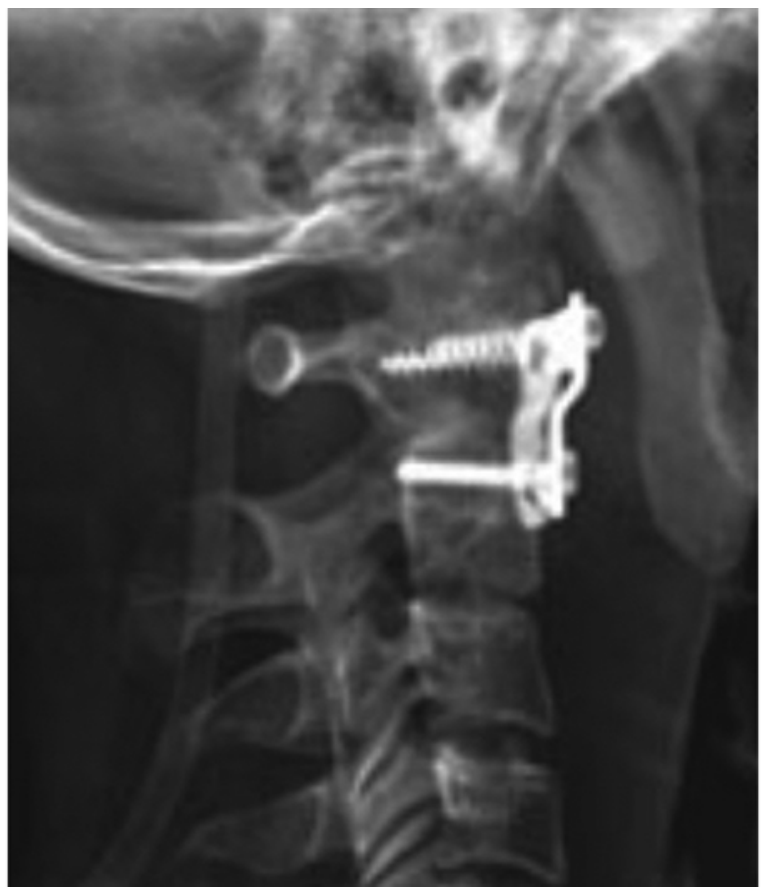

FIG. 1. Anterior C1-2 fusion construct. Modified from Yin et al: Transoral atlantoaxial reduction plate internal fixation for the treatment of irreducible atlantoaxial dislocation: a 2- to 4-year follow-up. Orthopedic Surg 2:149-155, 2010, with permission from Wiley. @ 2010 Tianjin Hospital and Blackwell Publishing Asia Pty Ltd.

by technical difficulties and concern for high complication rates, namely surgical site infection (SSI) after violating the posterior oral mucosa. ${ }^{18}$ Thus, the transoral approach is often abandoned in favor of posterior arthrodesis of the atlantoaxial spine (Fig. 2). Because of the paucity of data on this surgical technique, we present a 30-day outcome study comparing the transoral approach versus the posterior approach for fusing the atlantoaxial segment. The primary outcome measure was 30-day SSI, and the secondary outcome measure was 30 -day postoperative complications.

\section{Methods}

\section{Data Source and Patients}

The following description was adapted from our previous publication..$^{5}$ The source population was provided by the American College of Surgeons National Surgical Quality Improvement Program (ACS NSQIP) Participant Use File under a data use agreement. The database was queried for all patients who had undergone atlantoaxial fusion (Current Procedural Terminology [CPT] codes 22548 and 22595) between 2005 and 2014 (Fig. 3). With more than 250 participating international academic and nonacademic hospitals, NSQIP is a nationally validated, risk-adjusted, prospectively collected database that reports 30-day postoperative outcomes. ${ }^{11}$ Each hospital assigns a trained surgical clinical reviewer to collect perioperative clinical data on randomly assigned patients. Each hospital also assigns a "surgeon champion" to oversee accurate program implementation and ensure data reliability. To date, data on more than 2 million patients have been pro-

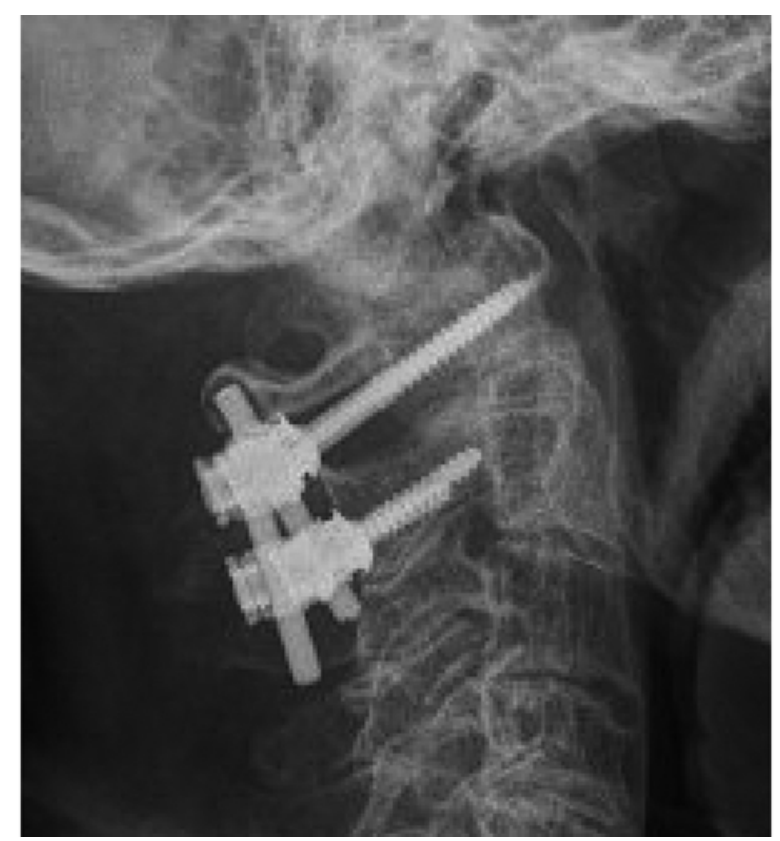

FIG. 2. Posterior instrumented fusion of the $\mathrm{C} 1-2$ junction.

spectively collected, including more than 60,000 neurosurgical cases. ACS NSQIP and the hospitals participating in ACS NSQIP are the source of the data used herein; they have not verified and are not responsible for the statistical validity of the data analysis or the conclusions derived by the authors.

In this study, spinal surgeries that extended arthrodesis to segments beyond the $\mathrm{C} 1-2$ levels were removed (Fig. 3 ), so the study population was limited to only the atlantoaxial spine. Circumferential operations (i.e., cases coded for both CPT 22548 and 22595) were eliminated to prevent cross-contamination of the matching scheme below. All patients underwent surgery for degenerative/spondylotic disease and/or trauma. Preoperative exclusion criteria removed conditions that could confound the risk of SSI: ventilated patients (an indwelling endotracheal tube may abrase the oropharyngeal mucosa) and patients with infected incision site, nonclean wound class, or sepsis.

\section{Matching Criteria}

Because of its technical difficulties, the transoral approach is far less common than the posterior approach to the atlantoaxial spine. To eliminate bias from unequal sample sizes, the patients who underwent the transoral approach were matched with patients who underwent the posterior approach based on age \pm 5 years and modified frailty index (mFI) score. For each anterior approach, we randomly selected up to 5 posterior approaches without replacement (i.e., each patient was only matched once). When fewer than 5 posterior surgeries were available for a given anterior surgery, we relaxed the matching criteria to at least 1 posterior surgery. Anterior operations without unmatched posterior counterparts were removed from the study criteria.

The burden of preoperative morbidity was determined by an algorithm that matched 16 variables in the NSQIP 
Years 2005 - 2013

Anterior Transoral Technique (Arthrodesis): CPT 22548

Intraoperative Exclusion of

Fusions:

-Anterior spinal segments below the C1-C2 levels: CPT 22551, 22552, 22554

-Posterior fusion below the C1-C2 levels: CPT 22600

-Posterior occipital cervical fusions: CPT 22590

-Circumferential fusions of both transoral and posterior surgery

Preoperative Exclusions:

-Ventilated patients

-Infected incision site

-Septic patients

-Wound Class $\neq$ clean

-Indication for surgery $\neq$

degenerative/spondylotic disease

and/or trauma

Arthrodesis, Posterior Technique, Atlas-Axis: CPT 22595

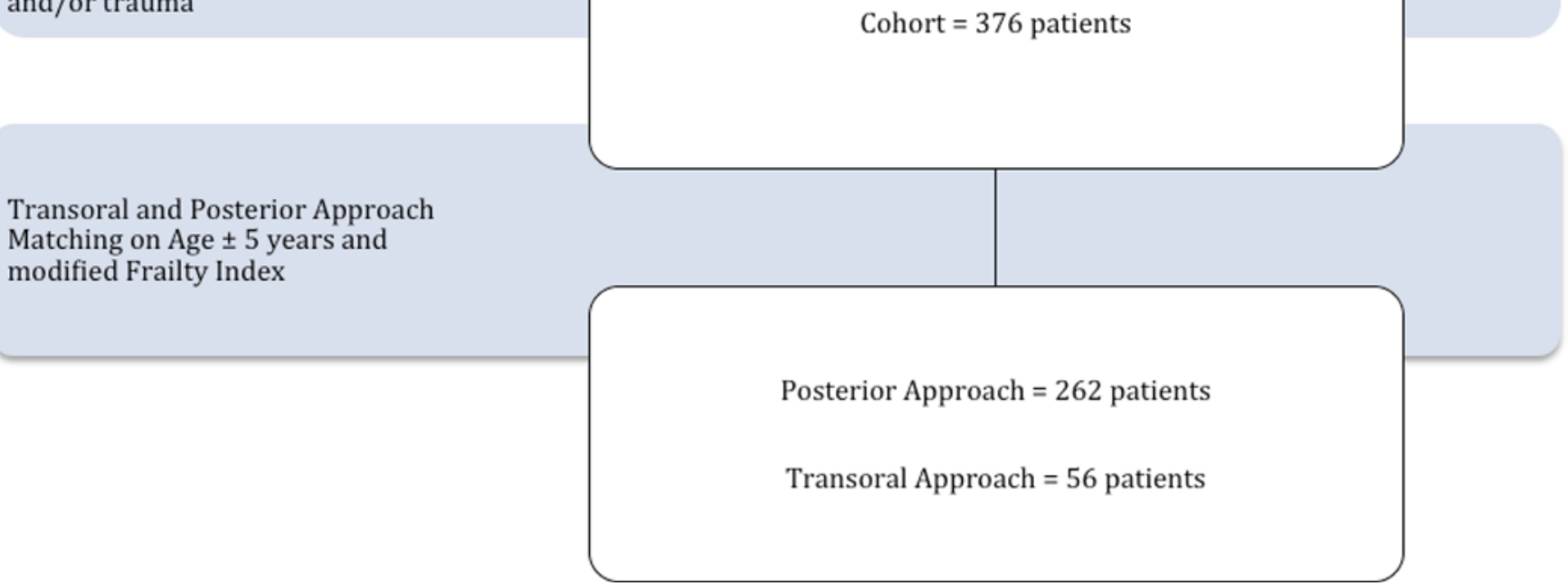

FIG. 3. Selection criteria for the study population. Figure is available in color online only.

database to 11 corresponding items in the Canadian Study of Health and Aging Frailty Index, which in turn was used to calculate mFI (Table 1). ${ }^{2}$ Developed by Tsiouris et al., ${ }^{25,26}$ this prevalidated risk assessment assigns 1 point to each variable in Table 1 . The sum of the points is divided by 11 to obtain the mFI score (range $0-1.0$ ), and a higher score presumes a greater comorbidity burden.

\section{Outcome Measure}

The primary outcome measure was 30-day SSI, which was a composite of superficial SSI, deep SSI, and/or organspace SSI. According to the NSQIP definitions, superficial
SSI only involves the skin or subcutaneous tissue of the incision as well as one of the following: 1) purulent drainage, with or without laboratory confirmation, from the superficial incision; 2) organisms isolated from an aseptically obtained culture from the superficial incision; and 3 ) at least one of the following signs or symptoms of infection-pain or tenderness, localized swelling, redness, or heat-and a superficial incision that was deliberately opened by the surgeon, unless the incision is culture negative. Deep SSI involves the deep soft tissues (e.g., fascial and muscle layers) of the incision as well as one of the following: 1) purulent drainage from the deep incision; 2) spontaneous dehiscence; 3 ) deliberate incisional opening 
TABLE 1. List of 11 variables used to develop $\mathrm{mFI}$

\begin{tabular}{l}
\hline \multicolumn{1}{c}{ Variable } \\
\hline Nonindependent functional status \\
\hline Diabetes mellitus \\
\hline COPD \\
\hline Congestive heart failure \\
\hline Myocardial infarction \\
\hline $\begin{array}{l}\text { Coronary artery disease (coronary intervention, cardiac surgery, } \\
\text { or angina) }\end{array}$ \\
\hline Hypertension requiring medication \\
\hline Peripheral vascular disease or rest pain \\
\hline Impaired sensorium \\
\hline Transient ischemic attack or stroke w/o neurological deficit \\
\hline Stroke w/ neurological deficit \\
\hline
\end{tabular}

$\mathrm{COPD}=$ chronic obstructive pulmonary disease.

by the surgeon when the patient had a fever $\left(>38^{\circ} \mathrm{C}\right)$, localized pain, or tenderness, unless the site is culture negative; or 4) an abscess or other evidence of infection involving the deep incision on direct examination, during reoperation, or on histopathological or radiological examination. Organ-space SSI involves any part of the anatomy (e.g., organs or spaces) other than the incision that was opened or manipulated during an operation and had at least one of the following: 1) purulent drainage from a drain that was placed through a stab wound into the organ space; 2) organisms isolated from an aseptically obtained culture of fluid or tissue in the organ space; or 3) abscess or other evidence of infection involving the organ space found on direct examination, during reoperation, or on histopathological or radiological examination.

A secondary outcome measure was 30-day postoperative complications, which was fitted into a binary outcome: aggregation of at least one of the postoperative complications listed in Table 2.

\section{Statistical Analysis}

The anterior operations and matched posterior operations were analyzed with descriptive statistics and are reported as the means $\pm \mathrm{SD}$ or frequencies and percentages (Table 2). Binary outcomes were compared using the chi-square test. Continuous outcomes were compared using the t-test. Because the incidence of SSI is rare $(<5 \%)$, 2 -way measures of the association between clinically relevant prognostic factors of SSI were calculated with penalized maximum likelihood estimation (firthlogit function), ${ }^{8}$ and the unadjusted odds ratios $\left(\mathrm{OR}_{\text {unadj }}\right)$ of the univariable regression analysis and the adjusted odds ratio $\left(\mathrm{OR}_{\text {adj }}\right)$ of the multivariable regression analysis are reported. ${ }^{12}$

\section{Sensitivity Analysis}

A binary regression model was fitted to the data to estimate the effect of the perioperative predictors on SSI. After an initial simple regression, predictors of SSI were calculated with multivariable logistic regression with forward stepwise modeling to report $\mathrm{OR}_{\mathrm{adj}}$. Each regression model tested in the forward stepwise approach was ana-
TABLE 2. Perioperative characteristics comparing the posterior approach and transoral approach in 318 fusions of the atlantoaxial segment

\begin{tabular}{|c|c|c|c|}
\hline Variable & $\begin{array}{l}\text { Posterior } \\
\text { Approach }\end{array}$ & $\begin{array}{l}\text { Transoral } \\
\text { Approach }\end{array}$ & $\begin{array}{c}p \\
\text { Value }\end{array}$ \\
\hline No. of fusions & 262 & 56 & \\
\hline Male sex & $125(47.71)$ & $33(58.93)$ & 0.127 \\
\hline Age, mean $\pm S D$, yrs & $61.13 \pm 17.34$ & $59.38 \pm 15.23$ & Matched \\
\hline \multicolumn{4}{|l|}{ Comorbidities } \\
\hline $\mathrm{mFI}$, mean $\pm \mathrm{SD}$ & $0.11 \pm 0.12$ & $0.10 \pm 0.11$ & Matched \\
\hline Steroid use 30 days preop & $24(9.16)$ & $1(1.79)$ & 0.063 \\
\hline Diabetes mellitus & $19(7.25)$ & $8(14.29)$ & 0.087 \\
\hline Hypertension & $137(52.29)$ & $29(51.79)$ & 0.945 \\
\hline Smoking & $44(16.79)$ & $15(26.79)$ & 0.081 \\
\hline Dyspnea & $15(5.73)$ & $4(7.14)$ & 0.685 \\
\hline COPD & $13(4.96)$ & $1(1.79)$ & 0.293 \\
\hline Congestive heart failure & $3(1.15)$ & $0(0)$ & 0.421 \\
\hline $\begin{array}{l}\text { Blood transfusion } \leq 72 \mathrm{hrs} \\
\text { preop }\end{array}$ & $1(0.38)$ & $0(0)$ & 0.643 \\
\hline Performed by neurosurgeon & $199(75.95)$ & $40(71.43)$ & 0.477 \\
\hline $\begin{array}{l}\text { Intraop blood transfusion } \\
\quad \leq 72 \text { hrs postop }\end{array}$ & $26(9.92)$ & 4 (7.14) & 0.518 \\
\hline $\begin{array}{l}\text { Length of hospital stay, } \\
\text { mean } \pm S D \text {, days }\end{array}$ & $4.72 \pm 4.36$ & $4.36 \pm 5.02$ & 0.581 \\
\hline \multicolumn{4}{|l|}{ Postoperative complications } \\
\hline Deep vein thrombosis & $1(0.38)$ & 0 & 0.643 \\
\hline Pulmonary embolus & $1(0.38)$ & 0 & 0.643 \\
\hline Pneumonia & $3(1.15)$ & $1(1.79)$ & 0.696 \\
\hline $\begin{array}{l}\text { Failure to extubate } \geq 48 \\
\text { hrs postop }\end{array}$ & $5(1.91)$ & $2(3.57)$ & 0.441 \\
\hline Reintubation & $4(1.53)$ & $1(1.79)$ & 0.888 \\
\hline Cerebral infarction & $1(0.38)$ & 0 & 0.643 \\
\hline Cardiac arrest & $1(0.38)$ & 0 & 0.643 \\
\hline Coma $\geq 24$ hrs postop & 0 & 0 & NA \\
\hline Sepsis & $1(0.38)$ & 0 & 0.643 \\
\hline Septic shock & $1(0.38)$ & 0 & 0.643 \\
\hline SSI & $5(1.91)$ & $1(1.79)$ & 0.951 \\
\hline Superficial SSI & $3(1.15)$ & $1(1.79)$ & 0.696 \\
\hline Deep SSI & $3(1.15)$ & 0 & 0.421 \\
\hline Organ/space SSI & 0 & 0 & NA \\
\hline Wound dehiscence & 0 & 0 & NA \\
\hline Unplanned reoperation & $4(1.53)$ & $3(5.36)$ & 0.076 \\
\hline $\begin{array}{l}\text { Composite postop com- } \\
\text { plication }\end{array}$ & $18(6.87)$ & $6(10.71)$ & 0.323 \\
\hline Unplanned readmission* & $7(3.33)$ & $4(9.76)$ & 0.066 \\
\hline
\end{tabular}

lyzed with a sensitivity analysis based on Akaike information criterion (AIC). AIC enables analysis of the tradeoff between the log-likelihood function and number of parameters, such that lower AIC values indicate a more robust model fit. ${ }^{1}$ Statistical significance was set at $\mathrm{p}<$ 
TABLE 3. Two-way measures of the association between prognostic factors for SSI calculated using penalized maximum likelihood estimation

\begin{tabular}{cccccc}
\hline \multirow{2}{*}{ Variable } & \multicolumn{2}{c}{ Univariate Regression } & & \multicolumn{2}{c}{ Multivariate Regression } \\
\cline { 2 - 3 } \cline { 5 - 6 } Male sex & $\mathrm{OR}_{\text {unadj }}$ & $\mathrm{p}$ Value & & $\mathrm{OR}_{\text {adj }}$ & $\mathrm{p} \mathrm{Value}$ \\
\hline Smoking & 3.81 & 0.149 & & 4.31 & 0.117 \\
\hline Approach $^{*}$ & 0.33 & 0.449 & & 0.26 & 0.368 \\
\hline
\end{tabular}

* Transoral versus posterior.

0.05. All statistical analyses were performed using Stata (version 14.1, StataCorp).

\section{Results}

Of the 318 study participants, 56 patients who underwent transoral atlantoaxial fusion were compared with 262 patients who underwent posterior atlantoaxial fusion (Table 2). The majority of surgeries were performed by neurosurgeons rather than orthopedic surgeons (75.16\%). The transoral cohort was matched with the posterior cohort based on age \pm 5 years and $\mathrm{mFI}$ score. The 2 cohorts did not statistically differ with regard to preoperative predictors: male sex $(p=0.127)$, steroid usage within 30 days prior to surgery $(\mathrm{p}=0.063)$, diabetes mellitus $(\mathrm{p}=0.087)$, hypertension $(\mathrm{p}=0.945)$, smoking $(\mathrm{p}=0.081)$, dyspnea $(\mathrm{p}=0.685)$, chronic obstructive pulmonary disease $(\mathrm{p}=$ $0.293)$, and congestive heart failure $(\mathrm{p}=0.421)$. No difference was detected in the number of preoperative blood transfusions $(\mathrm{p}=0.643)$ or intraoperative blood transfusions $(\mathrm{p}=0.518)$. Of the 318 patients, the average length of hospital stay was 4.66 days, without a difference between the 2 types of surgeries $(\mathrm{p}=0.581)$. Similarly, the transoral and posterior approaches did not statistically significantly differ in 30-day postoperative outcomes, including deep vein thrombosis $(\mathrm{p}=0.643)$, pulmonary embolus ( $\mathrm{p}$ $=0.643)$, pneumonia $(\mathrm{p}=0.696)$, failure to extubate $\geq 48$ hours after surgery $(p=0.441)$, reintubation $(p=0.888)$, cerebral infarction (i.e., stroke) $(\mathrm{p}=0.643)$, cardiac arrest $(p=0.643)$, sepsis $(p=0.643)$, and septic shock $(p=0.643)$. No patient experienced coma or wound dehiscence. Interestingly, the $1.79 \%$ incidence of 30-day SSI among patients who underwent the transoral approach did not statistically significantly differ with the $1.91 \%$ incidence among patients who underwent the posterior approach $(p=0.951)$. Following the posterior technique, 3 patients experienced superficial SSI and 3 patients experienced deep SSI, while 1 patient experienced a superficial SSI following the transoral technique. Following a sensitivity analysis of the multivariable regression models, the controlled variables in Table 3 generated the lowest AIC value (61.22). After controlling for sex and smoking, the odds of SSI in patients who underwent the transoral approach to the atlantoaxial spine were almost equal to the odds of the patients who underwent the posterior approach $\left(\mathrm{OR}_{\text {adj }} 1.17 ; \mathrm{p}=0.866\right)$.

While the unplanned reoperation rate of $5.36 \%(n=3)$ after transoral surgery was higher than the rate of $1.53 \%$ (n $=4$ ) after posterior surgery, the difference approached, but did not reach, statistical significance $(p=0.076)$. Indica- tions for unintended return to the operating room differed between the 2 groups. Reoperations following the posterior approach included evacuation of hematoma (same operative day), debridement followed by complex closure of deep SSI (postoperative Day 8), and incision and drainage of a seroma or fluid collection (postoperative Day 15), whereas the reoperations following the transoral approach included percutaneous tracheostomy because of failure to wean off the ventilator (postoperative Day 7) and removal of hardware because of instrumentation failure (postoperative Day 21). Indications were not specified for 1 patient each in the posterior and transoral groups.

Of 251 patients with 30-day readmission data, the $9.76 \%$ readmission rate following transoral surgeries was higher than the $3.33 \%$ readmission rate following posterior surgeries. Again, these differences approached, but did not reach, statistical significance $(\mathrm{p}=0.066)$. Two patients died within 30 days postoperatively in the posterior cohort: 1 patient on postoperative Day 1 and the other patient on postoperative Day 7. Lastly, 30-day postoperative morbidity (postoperative complications) was equivalent between patients who underwent transoral arthrodesis $(10.71 \%)$ and posterior arthrodesis $(6.87 \%)(\mathrm{p}=0.323)$.

\section{Discussion}

In the past, spine surgeons have avoided the transoral approach to the atlantoaxial segment because of concerns for unacceptable patient morbidity and mortality and notable infection rates when violating the oropharyngeal mucosa. ${ }^{6,17,22}$ In the 1980 s, however, publications on this anterior technique unveiled unexpectedly favorable outcomes. First, Menezes et al. published a case series of 72 patients who underwent the transoral-transpharyngeal approach to the craniocervical junction. ${ }^{17}$ Only 1 patient developed a wound infection following transoral resection of granulation tissue, causing odontoid invagination. Second, Hadley et al. published a case series of 53 patients who underwent a transoral approach to the superior cervical spine. ${ }^{13}$ Again, of the 44 indications for degenerative/spondylotic diseases and/or trauma, only 1 patient experienced SSI. Unfortunately, both cohorts lack internal validity because of the diversity of surgical indications, including tumors, degenerative/spondylotic diseases, and trauma. Nevertheless, these results corroborate the present study, in which only 1 patient experienced an SSI following transoral operations for degenerative/spondylotic spinal disease. However, these absolute numbers alone lack numerical significance and, more importantly, clinical application without a comparison reference. Thus, we compared transoral approaches to the more common posterior approaches to the atlantoaxial spine in a cohort study by matching patients for age \pm 5 years and exact mFI score. To circumvent fallacies associated with an inhomogeneous cohort, as in the aforementioned publications by Menezes et al. and Hadley et al., ${ }^{13,17}$ we limited the study population to only degenerative/spondylotic disease and/or trauma in hopes of strengthening the validity of the current study. The results were astonishing. Contrary to outdated beliefs, the incidence of SSI did not statistically significantly differ between transoral surgeries $(1.79 \%)$ and posterior surgeries 
$(1.91 \%)(p=0.951)$. Following a multivariable regression analysis, the approach to the atlantoaxial segment did not predict SSI $\left(\mathrm{OR}_{\text {adj }} 1.17 ; \mathrm{p}=0.866\right)$.

In a study of infection rates after applying the transoral approach to the upper cervical spine, Shousha et al. ${ }^{22}$ contends that the concern for increased SSI is unjustified for several reasons. First, just as only a few microbes in the skin flora have the potential for infections that are prophylactically prevented by cefazolin, only a few of the 200 microbes in the oral flora carry pathogenic capacity, most of which are anaerobes that may be treated by different prophylactic antibiotics (e.g., clindamycin). 3,10 Second, pharyngeal healing is far faster than skin healing. By postoperative Day 4, mucosal incisions are no longer visible. ${ }^{20}$ Third, the Waldeyer ring, a collection of lymph nodes in the pharynx, sustains a superior immunological environment; to that end, the oral tissue affords resistance to its own bacterial flora. ${ }^{4}$ As testament to these observations, the $1.79 \%$ infection incidence in the present study is comparable to the $1.9 \%$ infection incidence reported by Weinstein et al. in a review of 2391 consecutive spinal procedures performed through the skin. ${ }^{27}$

In the present study, postoperative morbidity was similar between transoral arthrodesis $(10.71 \%)$ and posterior arthrodesis $(6.87 \%)(\mathrm{p}=0.323)$. Equivalent complication rates between transmucosal versus extramucosal techniques have been well established in the otolaryngology and maxillofacial surgery literature. Upon examining 227 patients who underwent repair of mandibular fractures, Toma et al. reported "similar complication rates occurred for the transoral and extraoral approaches." ${ }^{24}$ Improvement in transmucosal morbidity owes more to rigorous preoperative planning, including antibiotic coverage of pharyngeal biograms, and abandoning preoperative tracheostomy in favor of carefully placed oral intubation tubes..$^{19}$ Regardless of the approach, however, morbidity after atlantoaxial surgery is slightly higher compared with subaxial spine surgery. In a study of 108,419 common spinal procedures, complication rates were $2.4 \%$ after anterior cervical discectomy and fusion $(n=6735)$ and $3.6 \%$ after posterior lumbar discectomy $(\mathrm{n}=9692){ }^{23}$ In this study, the total complication rate was $7.54 \%$ for atlantoaxial surgery. The higher complication rates are due to, in part, postoperative dysphagia after the anterior approach. In an institutional series on 533 operations with various transmucosal approaches to the atlantoaxial spine, Choi et al. found that the rates of dysphagia (range 0\%-3.3\% after the transoral approach) were among the highest for unintended outcomes? Damage to the oral mucosa and the pharyngeal constrictors contribute to transient odynophagia and mechanical dysphagia. Nevertheless, Choi et al. argue that "the incidence of serious complications is acceptable" because of the typically larger disease burden at the $\mathrm{C} 1-2$ level. These patients typically have remarkable findings of myelopathy, which emphasizes the importance of appropriately treating patients with $\mathrm{C} 1-2$ disease.

\section{Limitations}

Because transoral approaches are relatively rare, we attempted to reach appropriate statistical power using a large national data set and a matched-cohort design. As with all
NSQIP studies, these results are limited to 30-day postoperative outcomes. Also, the outcome of SSI is a rare event, the predictors of which may be difficult to ascertain. This was mitigated by the regression analysis that used penalized maximum likelihood estimation. While dysphagia is a reported complication after using the transoral approach to reach the atlantoaxial segment, this information was unfortunately unavailable in the NSQIP data set. Long-term outcomes should be ascertained by prospectively collected data obtained over several years.

\section{Conclusions}

In a matched-cohort study of 318 patients, the transoral approach for atlantoaxial fusion did not statistically significantly differ from the posterior approach in 30-day postoperative individual complications, including SSI and composite complications. Reoperation rates were marginally higher, but without statistical significance, following transoral surgery. Because unintended outcomes were equal between the 2 cohorts, spinal pathology, rather than concern for postoperative complications, should adjudicate the technical approach to the atlantoaxial segment.

\section{References}

1. Akaike H: A new look at the statistical model identification. IEEE Trans Automat Contr 19:716-723, 1974

2. Ali R, Schwalb JM, Nerenz DR, Antoine HJ, Rubinfeld I: Use of the modified frailty index to predict 30-day morbidity and mortality from spine surgery. J Neurosurg Spine 25:537-541, 2016

3. Ashraf J, Crockard HA: Transoral fusion for high cervical fractures. J Bone Joint Surg Br 72:76-79, 1990

4. Brandtzaeg P: Immune functions of nasopharyngeal lymphoid tissue. Adv Otorhinolaryngol 72:20-24, 2011

5. Bydon M, Abt NB, De la Garza-Ramos R, Macki M, Witham TF, Gokaslan ZL, et al: Impact of resident participation on morbidity and mortality in neurosurgical procedures: an analysis of 16,098 patients. J Neurosurg 122:955-961, 2015

6. Cantarella G, Mazzola RF, Benincasa A: A possible sequela of transoral approach to the upper cervical spine. Velopharyngeal incompetence. J Neurosurg Sci 42:51-55, 1998

7. Choi D, Crockard HA: Evolution of transoral surgery: three decades of change in patients, pathologies, and indications. Neurosurgery 73:296-304, 2013

8. Coveney J: Logistic regression in cases of separation by means of penalized maximum likelihood estimation, presented at the Summer North American Stata Users' Group Meetings 2008. (Abstract) (http://econpapers.repec.org/ paper/bocnsug08/10.htm) [Accessed June 23, 2017]

9. Crockard HA: The transoral approach to the base of the brain and upper cervical cord. Ann R Coll Surg Engl 67:321-325, 1985

10. Crockard HA: [Ventral approaches to the upper cervical spine.] Orthopade 20:140-146, 1991 (Ger)

11. Fink AS, Campbell DA Jr, Mentzer RM Jr, Henderson WG, Daley J, Bannister J, et al: The National Surgical Quality Improvement Program in non-veterans administration hospitals: initial demonstration of feasibility. Ann Surg 236:344-354, 2002

12. Firth D: Bias reduction of maximum likelihood estimates. Biometrika 80:27-38, 1993

13. Hadley MN, Spetzler RF, Sonntag VK: The transoral approach to the superior cervical spine. A review of 53 cases of extradural cervicomedullary compression. J Neurosurg 71:16-23, 1989 
14. Harms J, Schmelzle R, Stoltze D: Osteosynthesen im occipito-cervicalen Übergang vom transoralen Zugang aus, in XVII SICOT World Congress. Munich: Demeter Verlag, 1987, pp 32-33 (Abstract)

15. Kanavel A: Bullet located between the atlas and the base of the skull: technique of removal through the mouth. Surg Clin Chicago 1:361-366, 1917

16. Kandziora F, Schulze-Stahl N, Khodadadyan-Klostermann C, Schröder R, Mittlmeier T: Screw placement in transoral atlantoaxial plate systems: an anatomical study. J Neurosurg 95 (1 Suppl):80-87, 2001

17. Menezes AH, VanGilder JC: Transoral-transpharyngeal approach to the anterior craniocervical junction. Ten-year experience with 72 patients. J Neurosurg 69:895-903, 1988

18. Morgan S, Murphy G: The transoral approach to the cervical spine. J Neurosci Nurs 24:269-272, 1992

19. Mouchaty H, Perrini P, Conti R, Di Lorenzo N: Craniovertebral junction lesions: our experience with the transoral surgical approach. Eur Spine J 18 (Suppl 1):13-19, 2009

20. Salcman M, Jamaris J, Leveque H, Ducker TB: Transoral cervical corpectomy with the aid of the microscope. Spine (Phila Pa 1976) 4:209-212, 1979

21. Scoville WB, Sherman IJ: Platybasia, report of 10 cases with comments on familial tendency, a special diagnostic sign, and the end results of operation. Ann Surg 133:496-502, 1951

22. Shousha M, Mosafer A, Boehm H: Infection rate after transoral approach for the upper cervical spine. Spine (Phila Pa 1976) 39:1578-1583, 2014

23. Smith JS, Fu KM, Polly DW Jr, Sansur CA, Berven SH, Broadstone PA, et al: Complication rates of three common spine procedures and rates of thromboembolism following spine surgery based on 108,419 procedures: a report from the Scoliosis Research Society Morbidity and Mortality Committee. Spine (Phila Pa 1976) 35:2140-2149, 2010

24. Toma VS, Mathog RH, Toma RS, Meleca RJ: Transoral versus extraoral reduction of mandible fractures: a comparison of complication rates and other factors. Otolaryngol Head Neck Surg 128:215-219, 2003
25. Tsiouris A, Hammoud ZT, Velanovich V, Hodari A, Borgi J, Rubinfeld I: A modified frailty index to assess morbidity and mortality after lobectomy. J Surg Res 183:40-46, 2013

26. Velanovich V, Antoine H, Swartz A, Peters D, Rubinfeld I: Accumulating deficits model of frailty and postoperative mortality and morbidity: its application to a national database. J Surg Res 183:104-110, 2013

27. Weinstein MA, McCabe JP, Cammisa FP Jr: Postoperative spinal wound infection: a review of 2,391 consecutive index procedures. J Spinal Disord 13:422-426, 2000

28. Yin QS, Ai FZ, Zhang K, Mai XH, Xia H, Wu ZH: Transoral atlantoaxial reduction plate internal fixation for the treatment of irreducible atlantoaxial dislocation: a 2- to 4-year followup. Orthop Surg 2:149-155, 2010

\section{Disclosures}

The authors report the following. Dr. Abdulhak: consultant for SeaSpine and Johnson \& Johnson and owner of Innovative Surgical Solutions LLC. Dr. Lee: consultant for Medtronic and Monteris.

\section{Author Contributions}

Conception and design: Macki. Acquisition of data: Macki, Kather, Rubinfeld. Analysis and interpretation of data: Macki, Kather, Rubinfeld. Drafting the article: Macki. Critically revising the article: Macki, Basheer, Lee, Rubinfeld. Reviewed submitted version of manuscript: Macki, Basheer, Rubinfeld. Approved the final version of the manuscript on behalf of all authors: Macki. Statistical analysis: Macki. Administrative/technical/material support: Macki, Basheer, Lee, Abdulhak. Study supervision: Abdulhak.

\section{Correspondence}

Mohamed Macki, Department of Neurosurgery, Henry Ford Hospital, K11 Clinic, 2799 W Grand Blvd., Detroit, MI 48202. email: mmacki2@hfhs.org. 